\title{
Response to Tumor Necrosis Factor Inhibitors in Rheumatoid Arthritis for Function and Pain is Affected by Rheumatoid Factor
}

\author{
Babak Aberumand ${ }^{1,}$, Lillian Barra ${ }^{1}$, Yang Cao ${ }^{1,}$, Nicole Le Riche ${ }^{1}$, Andrew E. Thompson ${ }^{1}$, \\ Gina Rohekar ${ }^{1}$, Sherry Rohekar ${ }^{1}$, Ashley Bonner ${ }^{2}$ and Janet E. Pope ${ }^{*}, 1$ \\ ${ }^{I}$ Schulich School of Medicine \& Dentistry, University of Western Ontario, Department of Medicine, Division of \\ Rheumatology, St. Joseph's Health Care, Ontario, Canada \\ ${ }^{2}$ McMaster University, Hamilton, ON, Canada
}

\begin{abstract}
Objectives: To investigate differences in response to tumor necrosis factor inhibitor treatment (TNFi) in seropositive (rheumatoid factor positive; $\mathrm{RF}+$ ) versus seronegative (RF-) patients with established $\mathrm{RA}$ as measured by the Health Assessment Questionnaire Disability Index (HAQ-DI) and pain.

Methods: RA patients from an established RA cohort were studied according to rheumatoid factor (RF) status for change in HAQ-DI and pain (0-3 VAS) one year after starting treatment with a TNFi.

Results: There were 238 patients treated with TNFi who had follow-up data (178 RF+ and $60 \mathrm{RF}-$ ). Disease duration was longer in RF+ vs RF- (12 \pm 8 vs $8 \pm 8$ years) but the proportion of females $(82 \%$ ss $72 \%, \mathrm{P}=0.7)$, baseline HAQ-DI $(1.44 \pm 0.63$ vs $1.41 \pm 0.63, \mathrm{P}=0.8)$ and pain $(1.92 \pm 0.67$ vs $1.93 \pm 0.67, \mathrm{P}=0.9)$ were not different. The mean duration of treatment of first TNFi was 2.8 vs 2.3 years, $\mathrm{P}=0.1$ and $68 \%$ of $\mathrm{RF}+v s 62 \%$ of RF- were still receiving first TNFi at last visit $(\mathrm{P}=0.5)$. For patients with data at baseline and one year, the one-year HAQ-DI change was significantly greater in 90 $\mathrm{RF}+$ patients $(-0.356)$ versus $38 \mathrm{RF}$ - patients $(-0.126 ; \mathrm{P}=0.04)$. The mean pain improvement was also greater in $77 \mathrm{RF}+v s$ 32 RF- patients $(-0.725$ vs -0.332 respectively; $\mathrm{P}=0.03)$. Numbers are small, data are missing and comorbidities, DAS28 and anti-CCP were not collected.
\end{abstract}

Conclusion: Despite limitations in the data, in established RA after failure of DMARDs, RF+ patients may be more responsive to TNFi therapy as measured by changes in HAQ-DI and pain.

Innovation: There may be a better response to TNFi in RA if RF positive for function and pain.

Keywords: Adalimumab, etanercept, health assessment questionnaire disability index (HAQ-DI), infliximab, pain, response, rheumatoid arthritis (RA), rheumatoid factor (RF), tumour necrosis factor inhibitor (TNFi).

\section{INTRODUCTION}

Rheumatoid arthritis (RA) is often a disabling inflammatory arthritis [1]. Treatment includes use of disease modifying anti-rheumatic drugs (DMARDs) [2] and often biologics such as tumor necrosis factor inhibitors (TNFi) when DMARDs fail. TNFi improve joint counts and function, and reduce radiographic joint destruction [3]. The Health Assessment Questionnaire Disability Index (HAQDI) is a validated patient-completed questionnaire of functional impairment. Pain is measured in patients with various scales including a $15 \mathrm{~cm}$ long visual analog scale (VAS) and converted to a score from 0 to 3 [4]. Higher HAQ-DI scores in RA are associated with worse morbidity $[5,6]$. Conversely, improvements in HAQ-DI are associated with improved survival [7].

\footnotetext{
*Address correspondence to this author at the St. Joseph's Health Care, 268 Grosvenor St., London, ON, N6A 4V2, Canada; Tel: 519-646-6332;

Fax: 519-646-6334; E-mail: janet.pope@sjhc.london.on.ca

${ }^{\S}$ Babak Aberumand and Yang Cao are Canadian Rheumatology (CRA) Roche Research Summer Students.
}

Three-quarters of patients with established RA are seropositive for rheumatoid factor $(\mathrm{RF}+)$ [8]. Patients who are RF+ overall have a worse prognosis than RA patients who are RF negative (RF-) [9-11]. However, patients who are $\mathrm{RF}+$ respond more favorably to treatments such as rituximab $[12,13]$. Response to TNFi by RF status may be blunted in RF- patients [14], not different $v s \mathrm{RF}+$ [15] or more favorable in RF- patients [16]. Responses to tocilizumab and abatacept may be better in RF+ patients with RA [17].

The aim of this study was to determine whether the presence or absence of RF influences the response to TNFis with respect to function and pain in an observational cohort of real world patients with established RA over the first year of TNFi treatment.

\section{PATIENTS AND METHODS}

Patients with established RA beginning with TNFi treatment were recruited by rheumatologists at St. Joseph's Hospital Rheumatology clinic in London, Ontario, which is affiliated with Western University. Patients are primarily 
English speaking, representing the full spectrum of disease severity, and were generally followed from one to four times a year depending on disease severity and flares. Ethics approval was obtained from University of Western Ontario, to perform a chart audit on all patients in the clinic with RA who were started on a TNFi. Information regarding HAQDI, using a $15 \mathrm{~cm}$ VAS converted to a score from 0 to 3 was collected and duration of treatment was assessed on patients in our single center database (described elsewhere) [5]. Inclusion criteria were as follows: diagnosis of RA according to the revised ACR/EULAR criteria [18], laboratory proof of RF status within the chart, treatment initiation with etanercept, infliximab, and/or adalimumab; known start date of first TNFi and at least one follow up after TNFi. This allowed for calculation of mean treatment duration by RF status and the proportion of patients still receiving their first TNFi at the last follow up visit. Then analyses were performed with respect to the outcome measures of interest where patients needed at least one HAQ-DI score just prior to and at 1 year $( \pm 12$ weeks) of TNFi treatment. Pain scores where available (at initiation of TNFi and one year of TNFi treatment) were also analyzed. Only the data from the first TNFi treatment were used. Joint counts were not analyzed due to inter-observer variability, because different trainees having diverse expertise performed the joint counts that were recorded in the chart during routine visits. Charts of eligible patients were reviewed to determine if the rheumatoid factor lab result was available on the chart. Anti-CCP levels were not routinely collected as these patients had established RA often for years (before anti-CCP testing was available). The proportion of patients still taking the same TNFi at over time, and changes in HAQ-DI and pain (each on a 0-3 scale) (from one year of TNFi treatment minus baseline) were compared between RF positive and RF negative patients using Student t-tests (two-tailed, equal variance) and Chi square analyses.

Other parameters including patient age, disease duration, sex, baseline HAQ-DI and pain, and treatment duration were also compared between the RF positive and RF negative patients. All patients had been previously exposed to methotexate, most had used combination DMARDs (methotrexate with sulfasalzine and hydroxychloroquine), and leflunomide and very few had also used injectable gold salts, azathioprine and D-penicallamine. Comorbidities were not collected. DAS28 was not calculated due to lack of standardization of joint counts. The treatment start date was not always known as when TNFis were initially introduced, there was a long lag time between writing the prescription and obtaining the biologic; usually due to delayed reimbursement, so these patients were excluded. The chart audit had to contain a start date that could be determined within one month.

\section{RESULTS}

We identified 340 patients with RA receiving TNFis. In $22 \%$, RF status could not be confirmed by an actual laboratory report and $8 \%$ did not have a precise treatment start date for their first TNFi. Thus 238 RA patients with known RF status and a precise treatment start date and some follow up were included. Results are shown in Table 1. For those analyzed, the disease duration was longer in seropositive patients. Only 128 (54\%) had complete HAQ-DI scores just prior to TNFi introduction and 1 year after TNFi initiation and $109(46 \%)$ had paired pain scores. The majority of missing data at one year was due to treatment discontinuation prior to one year (approximately 23\%), occurrence of a visit that was not within a 12-week window of one year and missing data (i.e. HAQ-DI was not available at the key visits). Baseline HAQ-DI and pain were not different between seropositive and seronegative patients. The change in HAQ-DI was significantly greater in RF positive patients at -0.356 compared to -0.126 with RF negative patients $(\mathrm{P}=0.04)$. This was also true for pain where seropositive patients improved more at one year $(-0.725$ versus -0.332 ; $\mathrm{P}=0.03$ ). The mean treatment duration of the first TNFi was numerically longer but not significantly different in RF positive vs negative patients (2.8 years versus 2.3 respectively, $\mathrm{P}=0.1$ ) and similar proportions still were taking their first TNFi at last follow up.

\section{DISCUSSION}

This study found that the response to TNFi in patients with established RA who had previously failed multiple DMARDs was better for pain and function at one year in seropositive compared to RF negative patients; even though their baseline functional impairment and pain levels were similar prior to treatment with TNFi. The RF positive patients had longer disease duration; which may have affected the results as could other unknown confounding. However with longer disease duration, one would expect that more of the HAQ-DI would be irreversible due to more potential damage as HAQ-DI can reflect impaired function from damage and disease activity. There would be an expected bias for those with longer disease duration to have less reversibility of the HAQ-DI due to more potential damage, but the results were in the opposite direction. Both pain and function can be affected from multiple factors including comorbidities but since the baseline results were nearly identical between the two groups one can infer that the differences were due to differential effects of the TNFi treatment that was initiated.

Similar results were observed with infliximab treatment in a previous study where RA patients who were seropositive for either RF and/or anti-CCP experienced more improvement compared to seronegative patients. However, no specific cut off value for RF or anti-CCP could be determined to predict treatment response [14]. The reason for a potential differential response by RF status to some biologics is uncertain. It has been proposed that RF could impair drug clearance when large amounts of RF-monoclonal antibody complexes are formed [15]. RF-producing cells have been found in the inflamed rheumatoid synovium where it is believed that a TNFi can decrease local production of RF and this may correlate with a better treatment response $[19,20]$.

This was a single site study where many rheumatologists treated RA patients and the criteria for use of TNFi treatment is only after failure of high doses of methotrexate and often several other DMARDs. Disease duration was long, so misclassification of patients with RA was unlikely. The baseline HAQ-DI and pain values were similar in RF+ compared to RFgroups despite longer disease duration in the RF+ group so comorbities if different between the two groups did not affect function and pain just before TNFi use. There are several limitations. Some data were missing with regards to patient RF status, and thus, these patients were excluded from analyses. 
Table 1. Summary of demographic information for established RA patient cohort receiving TNF inhibitors and response with respect to health assessment questionnaire disability index (HAQ-DI) and pain.

\begin{tabular}{|c|c|c|c|}
\hline Established RA TNFi Treatment & $\begin{array}{l}\text { Rheumatoid Factor } \\
\text { Positive (RF+) }\end{array}$ & $\begin{array}{l}\text { Rheumatoid Factor } \\
\text { Negative (RF-) }\end{array}$ & P Value \\
\hline $\begin{array}{l}\text { Total } N \text { with RF results available }(238) \\
\text { (\% of included patients) }\end{array}$ & $178(75 \%)$ & $60(25 \%)$ & \\
\hline$\%$ Female & $82 \%$ & $72 \%$ & 0.7 \\
\hline Age (SD) & $57 \quad(14)$ & $56 \quad(12)$ & 0.6 \\
\hline Disease duration $\{$ years $\}$ (SD) & $12 \quad(8)$ & $9 \quad(8)$ & 0.017 \\
\hline $\begin{array}{l}\mathrm{N} \text { with available paired HAQ-DI results at } 1 \text { year\# ( } \% \text { of included patients) } \\
\mathrm{N} \text { included } 128\end{array}$ & $90(70 \%)$ & $38(30 \%)$ & \\
\hline $\begin{array}{l}\text { Baseline HAQ-DI }(\mathrm{SD}) \\
(0=3) \text { prior to TNFi }\end{array}$ & $1.44 \quad(0.63)$ & $1.41 \quad(0.63)$ & 0.8 \\
\hline HAQ-DI change Baseline to Year 1 & $-0.356(0.60)$ & $-0.126(0.54)$ & 0.04 \\
\hline $\begin{array}{l}\mathrm{N} \text { with available paired Pain results at } 1 \text { year }^{\#} \text { (\% of included patients) } \\
\mathrm{N} \text { included } 109\end{array}$ & $77(71 \%)$ & $32(29 \%)$ & \\
\hline $\begin{array}{l}\text { Baseline PAIN (SD) } \\
(0-3)\end{array}$ & $1.92 \quad(0.67)$ & $1.93 \quad(0.67)$ & 0.9 \\
\hline PAIN change Baseline to Year 1 & $-0.725(0.86)$ & $-0.332(0.82)$ & 0.03 \\
\hline $\begin{array}{l}\text { Mean treatment duration for first TNFi }\{\text { Years }\} \text { (SD) } \\
\mathrm{N}=238\end{array}$ & $2.8 \quad(2.0)$ & $2.3 \quad(1.6)$ & 0.1 \\
\hline $\begin{array}{l}\text { Proportion of patients still on same TNFi after at last follow up from the included } 238 \\
\text { patients }\end{array}$ & $68 \%$ & $62 \%$ & 0.5 \\
\hline
\end{tabular}

Note of 340 identified patients, only 238 had some data available for analysis. SD = Standard Deviation; Age and Disease Duration is shown in Years; p-Value with significance at $<0.05$, \#nly the patients with available data compose the $\mathrm{N}$ for each result. The demographics (age, sex, disease duration, baseline HAQ-DI, baseline pain) of the patients with available data was not significantly different from those with incomplete data.

Anti-CCP was missing for the majority of patients and thus not analyzed. Selection bias for TNFi prescription likely was present (but should not have been different in RF+ and RFpatients as demonstrated by similar baseline HAQ-DI and pain scores). RF status was confirmed in only 258 out of 340 patients and many patients had missing HAQ-DI or pain scores. However, demographics for patients included vs not included were not significantly different. Ideally anti-CCP should also be compared to determine if in prevalent RA there is a differential response to TNFi by anti-CCP status. Perhaps longer treatment could yield different results such as potentially in durability of response for seropositive $v s$ seronegative patients. Our study is too underpowered to answer whether RF status affects the sustainability of treatment. The major changes in HAQ-DI and pain are early with TNFi treatment so our study is long enough for early treatment changes to be detected on these measures but whether the differences continue beyond a year is not known.

Perhaps, patients that are RF negative with established RA have a blunted response to several biologics including TNFi, and also rituximab and tocilizumab after failure of DMARDs [17]. The data do not agree with all studies. ACR20 and DAS28 responses from a meta-analysis of TNFi, did not find different responses in patients based on their rheumatoid factor status [15].

\section{CONCLUSION}

TNFi treatment varies between RF positive and negative patients with respect to changes in function and pain in this cohort and this has not been fully appreciated previously. Future studies should continue to explore differential responses by readily available biomarkers.

\section{CONFLICT OF INTEREST}

The authors confirm that this article content has no conflict of interest.

\section{ACKNOWLEDGEMENTS}

Partial funding for this project was through the Program of Experimental Medicine, Department of Medicine, Schulich School of Medicine, University of Western Ontario. Ethics approval was obtained from the University of Western Ontario, Ethics Review Board.

\section{REFERENCES}

[1] Verschueren P, Esselens G, Westhovens R. Predictors of remission, normalized physical function, and changes in the working situation during follow-up of patients with early rheumatoid arthritis: an observational study. Scand J Rheumatol 2009; 38: 166-72.

[2] Makinen H, Kautiainen H, Hannonen P, et al. Sustained remission and reduced radiographic progression with combination disease modifying antirehumatic drugs in early rheumatoid arthritis. J Rheumatol 2007; 34: 316-21.

[3] Rubbert-Roth A, Finckh A. Treatment options in patients with rheumatoid arthritis failing initial TNF inhibitor therapy: a critical review. Arthritis Res Ther 2009; 11(Suppl 1): S1.

[4] Fries JF, Spitz P, Kraines RG, Holman HR. Measurement of patient outcomes in arthritis. Arthritis Rheum 1980; 23: 137-45. 
[5] Barra L, Pope JE, Payne M. Real-world anti-tumour necrosis factor treatment in rheumatoid arthritis, psoriatic arthritis, and ankylosing spondylitis: cost-effectiveness based on number needed to treat to improve health assessment questionnaire. J Rheumatol 2009; 36: 14218.

[6] Farragher TM, Lunt M, Bunn DK, Silman AJ, Symmons DP. Early Functional disability predicts both all-cause and cardiovascular mortality in people with inflammatory polyarthritis: results from the Norfolk Arthritis Register. Ann Rheum Dis 2007; 66: 486-92.

[7] Yelin E, Trupin L, Wong B, Rush S. The impact of functional status and change in functional status on mortality over 18 years among persons with rheumatoid arthritis. J Rheumatol 2002; 29: 1851-7.

[8] Goldbach-Mansky R, Lee J, McCoy A, et al. Rheumatoid arthritis associated autoantibodies in patients with synovitis of recent onset. Arthritis Res 2000; 2: 236-43.

[9] Miriovsky BJ, Michaud K, Thiele GM, et al. Anti-CCP antibody and rheumatoid factor concentrations predict greater disease activity in men with rheumatoid arthritis. Ann Rheum Dis 2010; 69: 1292-7.

[10] Bas S, Genevay S, Meyer O, Gabay C. Anti-cyclic citrullinated peptide antibodies, $\operatorname{IgM}$ and $\operatorname{IgA}$ rheumatoid factors in the diagnosis and prognosis of rheumatoid arthritis. Rheumatology (Oxford) 2003; 42: 677-80.

[11] Vittecoq O, Pouplin S, Krzanowska K, et al. Rheumatoid factor is the strongest predictor of radiological progression of rheumatoid arthritis in a three-year prospective study in community-recruited patients. Rheumatology (Oxford) 2003; 42: 939-46.

[12] Emery P, Keystone E, Tony HP, et al. IL-6 receptor inhibition with tocilizumab improves treatment outcomes in patients with rheumatoid arthritis refractory to anti-tumour necrosis factor biological: results from a 24-week multicenter randomized placebo-controlled trial. Ann Rheum Dis 2008; 67: 1516-23.
[13] Tak PP, Rigby W, Rubbert-Roth A, et al. Sustained inhibition of progressive joint damage with rituximab plus methotrexate in early active rheumatoid arthritis: 2-year results from the randomized controlled trial IMAGE. Ann Rheum Dis 2012; 71: 351-7.

[14] Klaasen R, Cantaert T, Wiibrandts CA, et al. The value of rheumatoid factor and anti-citrullinated protein antibodies as predictors of response to infliximab in rheumatoid arthritis: an exploratory study. Rheumatology (Oxford) 2011; 50: 1487-93.

[15] Salgado E, Maneiro JR, Carmona L, Gomez-Reino J. Rheumatoid factor and response to TNF antagonists in rheumatoid arthritis: Systematic review and meta-analysis of observational studies. Joint Bone Spine 2014;81:41-50.

[16] Bobbio-Pallavinci F, Caporali R, Alpini C, Moratti, Montecucco C. Predictive value of antibodies to citrullinated peptides and rheumatoid factors in anti-TNF-alpha treated patients. Ann N Y Acad Sci 2007; 11 287-95.

[17] Maneiro RJ, Salgado E, Carmona L, Gomex-Reino JJ. Rheumatoid factor as predictor of response to abatacept, rituximab and tocilizumab in rheumatoid arthritis: Systematic review and meta-analysis. Semin Arthritis Rheum 2013; 42: 9-17.

[18] Aletaha D, Neogi T, Silman AJ, et al. 2010 rheumatoid arthritis classification criteria: an American College of Rheumatology/European League Against Rheumatism collaborative initiative. Ann Rheum Dis 2010; 69: 1580-8.

[19] Reparon-Schuiit CC, van Esch WJ, van Kooten C, Levarht EW, Breedveld FC, Verweij CL. Functional analysis of rheumatoid factorproducing B cells from the synovial fluid of rheumatoid arthritis patients. Arthritis Rheum 1998; 41: 2211-20.

[20] Nozaki Y, Nagare Y, Hino S, et al. Therapeutic strategy and significance of serum rheumatoid factor in patients with rheumatoid arthritis during infliximab treatment. Nihon Rinsho Meneki Gakkai Kaishi 2010; 33: 135-41.

(C) Aberumand et al.; Licensee Bentham Open.

This is an open access article licensed under the terms of the Creative Commons Attribution Non-Commercial License (http://creativecommons.org/licenses/by-nc/ 3.0/) which permits unrestricted, non-commercial use, distribution and reproduction in any medium, provided the work is properly cited. 